\title{
Electrophysiological Evaluation of an Anticancer Drug Gemcitabine on Cardiotoxicity Revealing Down-regulation and Modification of the Activation Gating Properties in the Human Rapid Delayed Rectifier Potassium Channel
}

\section{Mengyan Wei}

Oita University: Oita Daigaku

\section{Pu Wang}

Oita University: Oita Daigaku

Xiufang Zhu

Oita University: Oita Daigaku

Yangong Liu

Oita University: Oita Daigaku

Mingqi Zheng

Hebei Medical University

Gang Liu

Hebei Medical University

Hiroki Osanai

Oita University: Oita Daigaku

Kenshi Yoshimura

Oita University: Oita Daigaku

Shinichiro Kume

Oita University: Oita Daigaku

Tatsuki Kurokawa

Oita University: Oita Daigaku

Katsushige Ono ( $\nabla$ ono@oita-u.ac.jp )

Oita University: Oita Daigaku https://orcid.org/0000-0001-7949-1823

\section{Research Article}

Keywords: gemcitabine, hERG, glycosylation, IKr; post-translational regulation, cardio-oncology, rapid delayed rectifier potassium channel, $\mathrm{Kv} 11.1, \mathrm{KCNH} 2$ 
Posted Date: December 1st, 2021

DOI: https://doi.org/10.21203/rs.3.rs-1114008/v1

License: (c) (i) This work is licensed under a Creative Commons Attribution 4.0 International License. Read Full License 


\section{Abstract}

Gemcitabine is an antineoplastic drug commonly used in the treatment of several types of cancers including pancreatic cancer and non-small cell lung cancer. Although gemcitabine-induced cardiotoxicity is widely recognized, the exact mechanism of cardiac dysfunction causing arrhythmias remains unclear. The objective of this study was to electrophysiologically evaluate the proarrhythmic cardiotoxicity of gemcitabine focusing on the human rapid delayed rectifier potassium channel, hERG channel. In heterologous expression system in HEK293 cells, hERG channel current $\left(I_{h E R G}\right)$ was reduced by gemcitabine when applied for $24 \mathrm{~h}$ but not immediately after the application. Gemcitabine modified the activation gating properties of the hERG channel toward the hyperpolarization direction, while inactivation, deactivation or reactivation gating properties were unaffected by gemcitabine. When gemcitabine was applied to hERG-expressing HEK293 cells in combined with tunicamycin, an inhibitor of $\mathrm{N}$-acetylglucosamine phosphotransferase, gemcitabine was unable to reduce $I_{h E R G}$ or shift the activation properties toward the hyperpolarization direction. Our results suggest the possible mechanism of arrhythmias caused by gemcitabine revealing a down-regulation of $I_{h E R G}$ through the post-translational glycosylation disruption that alters the electrical excitability of cells.

\section{Introduction}

Gemcitabine is an antineoplastic drug, which is commonly used particularly to treat several types of solid organ malignancies such as pancreatic cancer, non-small cell lung cancer, and breast cancer [1]. One of the drug profiles that differentiate antineoplastic pharmacological therapies from other pharmacological therapies is the frequency and severity of adverse effects at clinical application. The most common adverse effects of gemcitabine are symptoms in gastrointestinal, hepatic and hematopoietic disorders including nausea, vomiting, increased alanine aminotransferase (ALT) and aspartate aminotransferase (AST), increased alkaline phosphatase, anemia, and thrombocytopenia [2]. Furthermore, gemcitabine is also known to cause cardiovascular adverse reactions including myocardial ischemia, pericardial diseases, heart failure, and arrhythmias [2]. Among them, supraventricular tachyarrhythmias, especially atrial fibrillation often occur in cancer patients with gemcitabine therapy $[3,4]$. There is increasing recognition that the association of gemcitabine with atrial fibrillation is strong and can occur even after the first dose, suggesting that gemcitabine could interact with arrhythmogenic substrates in the heart.

Drug interactions with cardiac ion channels are the underlying mechanisms for the occurrence of arrhythmias. Although rare, association of gemcitabine with QT interval prolongations in electrocardiogram (ECG) was also reported in several studies [5-8]. QT interval prolongation is actually not considered to be a toxic substrate, however, this electrical derangement has been observed in human subjects just prior to the onset of cardiac arrhythmias. Co-occurrence of QT interval prolongation and arrhythmias has led to a postulated link between QT and arrhythmogenic ion channel dysregulation. One of the primary causes of drug-induced QT interval prolongation is thought to be blockage of the hERG potassium channel in cardiac myocytes [9]. Of note, multiple recent studies have concluded that prolonged QT interval has an increased risk of atrial fibrillation [10-14]. 
In the present study, we electrophysiologically evaluated the action of gemcitabine as a potential modulator of cellular excitability focusing on the hERG channel, with the aim of understanding mechanism for atrial fibrillation and QT interval prolongation as a major cardiotoxicity of this drug.

\section{Materials And Methods}

The experimental protocol was approved as "a non-animal study" in advance by the Ethics Review Committee for Animal Experimentation of Oita University School of Medicine.

\subsection{Cell Preparation}

The human embryonic kidney 293 (HEK293) cells stably expressing the hERG channel (hERG-HEK293) are generous gifts from Professor Imaizumi, Nagoya City University, Japan. hERG-HEK cells were cultured in Dulbecco's modified Eagle's medium (DMEM, Hyclone, Logan, UT, USA) with $15 \%$ fetal bovine serum (FBS, Gibco) at $37^{\circ} \mathrm{C}$ and exposed to an atmosphere of $5 \% \mathrm{CO}_{2}$. The culture medium was also supplemented with $400 \mu \mathrm{g} \cdot \mathrm{mL}^{-1}$ gentamycin (G418, Calbiochem, USA). hERG-HEK cells were treated with acute- $(5 \mathrm{~min})$ and long-term $(24 \mathrm{~h})$ perfusion of gemcitabine for detection of the drug actions on $I_{h E R G}$ and the hERG channel gating properties.

\subsection{Electrophysiological recording}

We used a whole-cell patch clamp technique for the measurement of $I_{h E R G}$ according to the previous studies [15-17]. Briefly, I I by Pulse ver.8 software (HEKA Eletronik, Lambrecht, Germany). Patch pipettes were pulled from 75-mm plain capillary tubes (Drummond Scientific Co., Broomall, PA, USA) by Model P-97 (Sutter Instrument Co., Novato, CA, USA), and were heat-polished subsequently to achieve the pipette resistance at 2-4 $\mathrm{M} \Omega$ when filled with the pipette solution shown below. Series resistance was compensated by at least $80 \%$ and was continually monitored throughout the experiment. All the current measurements were done at room temperature $\left(20-23^{\circ} \mathrm{C}\right)$. For the current recording, the chamber was filled with bath solution contained $(\mathrm{mM}) \mathrm{NaCl} 135, \mathrm{KCl} 5, \mathrm{MgCl}_{2} 1, \mathrm{CaCl}_{2} 2$, HEPES 10, glucose 10 (pH 7.4 by $\left.\mathrm{NaOH}\right)$. The patch electrodes were filled with pipette solution consists of $(\mathrm{mM}) \mathrm{KCl} 135, \mathrm{MgCl}_{2} 1$, EGTA 5 and HEPES $10(\mathrm{pH}$ 7.2 by $\mathrm{KOH}$ ). For analysis of the conductance-voltage relationship or $I_{\text {hERG.tair }} V$ relationship, tail current of $I_{h E R G}$ was evoked through a 4-s voltage step to $-40 \mathrm{mV}$, following a 4-s depolarization step with a $10 \mathrm{mV}$ stepwise increase from -80 to $60 \mathrm{mV}$, which was initiated after a holding potential of $-80 \mathrm{mV}$ (Figure 1). The peak of the outward tail current of $I_{h E R G}$ were plotted against the voltage of test pulses, and the data were fitted to the Boltzmann function, as: $f(V)=1 /\left(1+e\left[\left(V_{1 / 2}-V\right) / k\right]\right)+C$, where the $V_{1 / 2}$ value is the membrane potential when the relationship reaches half level, and the $\mathrm{k}$ value is the slope factor. $\mathrm{C}$ is a constant component. For analysis of the activation gating properties, we used an envelope of tails procedure, which takes advantage of the fact that although at potentials positive to approximately +30 $\mathrm{mV}$ a small and brief transient component of inactivation overlaps with activation [18], recovery from inactivation is rapid [19] and deactivation is relatively slow [20]. The activating kinetics were evaluated by 
plotting the plotted the activating inward tail current envelope as a function of test pulse duration by use of a single exponential equation fits, which provided the time constant $\left(\tau_{\text {act }}\right)$ for activation at each individual potential, based on the simple Hodgkin and Huxley model [9] (Scheme I). Namely, hERG-HEK cells were evoked through a depolarization step, from $-10 \mathrm{mV}$ to $+30 \mathrm{mV}$, for an incremental duration for $20 \mathrm{~ms}-4,000 \mathrm{~ms}$ followed by a holding potential of $-100 \mathrm{mV}$. At each depolarizing potential, $\tau_{\text {act }}$ was then plotted against the depolarizing voltage, yielding $\tau_{\text {act }}$-voltage relationship (Figure 3 ). For analysis of the inactivation gating properties, the inactivating kinetics were evaluated by the time constant of the tail current; hERG-HEK cells were evoked through a 2.5-s depolarizing steps (test potentials) from $-60 \mathrm{mV}$ to $+60 \mathrm{mV}$ to inactivate, following a $5-\mathrm{ms}$ repolarization at $-120 \mathrm{mV}$ from the holding potential of $+60 \mathrm{mV}$ (Scheme I). At each test potential, onset of each inactivation current or the decay of tail current during each voltage step was fitted by use of a single exponential curve, which provided the time constant for inactivation ( $\tau_{\text {inact }}$ ) at the individual potentials, then $\tau_{\text {inact }}$ was plotted against the voltage, yielding $\tau_{\text {inact }}{ }^{-}$ voltage relationship (Figure 4). For analysis of the deactivation gating properties, the deactivating kinetics were evaluated by fitting the deactivating inward tail current at each repolarizing voltage step $(-180 \mathrm{mV}$ to $-110 \mathrm{mV}$ ) from the holding potential of $+60 \mathrm{mV}$ to a single exponential curve (Scheme I), providing the time constant for deactivation ( $\tau_{\text {deact }}$ ) at the individual potentials, then $\tau_{\text {deact }}$ was plotted against the voltage, yielding $\tau_{\text {deact }}$-voltage relationship (Figure 5). For analysis of the reactivation gating properties namely recovery from the inactivation gating properties, the reactivating kinetics were evaluated by the amplitude of peak tail current corresponding to the hyperpolarizing pulse from $-200 \mathrm{mV}$ to $+60 \mathrm{mV}$ for 5 ms to allow inactivation to recovery to a steady-state (Scheme I), followed by a return step to $+60 \mathrm{mV}$ (Figure 6).

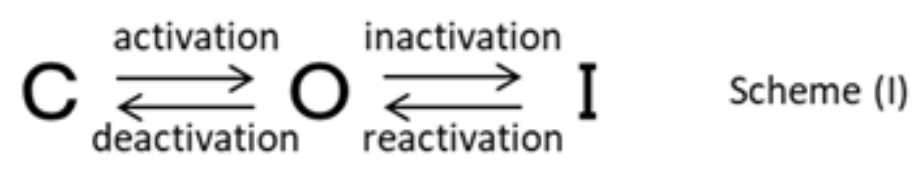

The peak of the tail currents plotted as a function of the preceding test pulse potentials were fitted with a Boltzmann function, namely the steady-state inactivation curve, was assessed as the reactivation kinetics. At more negative voltages from $-170 \mathrm{mV}$ to $-200 \mathrm{mV}$, a proportion of the hERG channels also deactivate during the $5 \mathrm{~ms}$ test potential, leading the observed decrease in the peak $I_{h E R G}$ at negative potentials. Therefore, before fitting of the Boltzmann equation, this deactivation was corrected based on the pulse protocol in Figure 5. For analysis of the concentration dependency of gemcitabine on $I_{h E R G}$, we used six concentrations of gemcitabine $(0.01,0.05,0.1,1,5$, and $50 \mu \mathrm{M})$ to construct the half-maximal inhibitory concentration $\left(\mathrm{IC}_{50}\right)$ curve, which was sigmoidal in shape plotted against the log [gemcitabine] fitted with the Hill equation.

\subsection{Chemicals}

All chemicals were purchased from Wako Pure Chemical Industries (Osaka, Japan). Gemcitabine was dissolved in dissolved in dimethyl sulfoxide (DMSO) as stock solutions (50 mM), and then diluted to final 
concentrations in cell culture solutions. The final concentration of DMSO or acetic acid in the bathing solution was $0.01 \%$ or less.

\subsection{Statistical analysis}

All data are presented mean \pm SE. Statistical analysis was performed by one-way ANOVA with TukeyKramer test or Dunnett's post hoc test. To assess the differences in two groups, unpaired Student's $t$ test was performed. $\mathrm{EC}_{50}$ values were estimated by using non-linear least square curve-fitting programs in Sigma plot software ver.10 (SPSS, Chicago, IL, USA). Differences were considered significant when $p$ values were less than 0.05 if nothing else is mentioned.

\section{Results}

\subsection{Acute- and long-term effect $t$ of gemcitabine on IhERG}

We first examined the possible acute effect of gemcitabine on $I_{\text {hERG. }}$. Human embryonic kidney 293 (HEK293) cells stably expressing the hERG channel (hERG-HEK cells) were superfused with normal Tyrode's solution and the membrane potential was held at $-80 \mathrm{mV}$ followed by test pulses with a duration of $4 \mathrm{~s}$, and then voltage-clamped at the potentials of $-40 \mathrm{mV}$ for $4 \mathrm{~s}$ (Figure 1, inset). Figure $1 \mathrm{~A}$ illustrates typical acute effects of gemcitabine $(50 \mu \mathrm{M})$ for 5 min on $I_{h E R G}$ family, demonstrating a negligible action of gemcitabine on $I_{h E R G}$ (also in Supplemental table 1). Effect of gemcitabine on the terminal $I_{h E R G}$ at the end of the test pulse of $4 \mathrm{~s}$ (indicated by hollow arrowheads) were plotted against the membrane potentials imposed ( $I_{\text {hERG.term }}-V$ relationship), and summarized in Figure 1B. Effect of gemcitabine on the maximum tail $I_{h E R G}$ at the beginning of the pulse at $-40 \mathrm{mV}$ (indicated by filled arrowheads) following the test potentials were plotted against the membrane potentials imposed ( $I_{\text {hERG.tai }} V$ relationship), and summarized in Figure 1C. The amplitude of the maximum outward $I_{h E R G . t e r m}$, the bell-shaped $I_{h E R G . t e r m}-V$ relationship or the maximum $I_{h E R G \text {.tail }}$ was unchanged by gemcitabine. According to these results, it is concluded that gemcitabine has substantially no actions on $I_{h E R G}$ as assessed at 5 min after application.

We then assessed the action of gemcitabine on $I_{h E R G}$ as applied in the culture medium for hERG-HEK cells for $24 \mathrm{~h}$. Figure 1D indicates representative samples of $I_{h E R G}$ family recorded with or without actions of gemcitabine $(50 \mu \mathrm{M})$ for $24 \mathrm{~h}$, demonstrating a long-term inhibitory effect of gemcitabine on $I_{h E R G}$. Note that the solution was changed to gemcitabine-free bath solution in this patch-clamp study. The $I_{h E R G . t e r m}{ }^{-}$ $V$ relationship revealed a long-term reduction of $I_{\text {hERG }}$ by gemcitabine for $24 \mathrm{~h}$; terminal $I_{\text {hERG }}$ was reduced by $53 \%(50 \mu \mathrm{M})$ as assessed by the maximum outward current at $+10 \mathrm{mV}$ or $+20 \mathrm{mV}$ (Figure 1E). The $I_{h E R G \text {.tair }} V$ relationship revealed a long-term reduction of $I_{h E R G}$ as well by gemcitabine for $24 \mathrm{~h}$; the tail $I_{\text {hERG }}$ was reduced by $52 \%(50 \mu \mathrm{M})$ as assessed by the maximum outward current at $+60 \mathrm{mV}$ (Figure $1 \mathrm{~F}$ ). Interestingly, the half-activation potential $\left(V_{1 / 2 . a c t}\right)$ was significantly changed by gemcitabine treatment; $V_{1 / 2 . a c t}$ was $0.05 \pm 0.80 \mathrm{mV}$ in vehicle and $-5.37 \pm 1.40 \mathrm{mV}$ by gemcitabine $(50 \mu \mathrm{M})$ treatment, which 
suggests that gemcitabine not only suppresses $I_{h E R G}$ but also modifies the gating properties of the channel.

\subsection{Concentration-dependent suppression of $\mathrm{I}_{\mathrm{hERG}}$ by gemcitabine}

Dose-dependent suppression of $I_{\mathrm{hERG}}$ by gemcitabine was constructed by measuring percentage suppression of the maximum tail current of $I_{\mathrm{hERG}}$ with various concentration of gemcitabine (Figure 2 and Supplemental table 2). As indicated by representative current families of $I_{h E R G}$ (Figure 2A), the hERG-HEK cells display lower $I_{h E R G}$ amplitude when gemcitabine concentration was increased. The $I_{\text {hERG.tair }} V$ relationship revealed a clear dose-dependency of gemcitabine actions on inhibition of $I_{h E R G}$ (Figure 2B). Importantly, $\mathrm{V}_{1 / 2 \text {.act }}$ was also changed in a concentration-dependent manner; $\mathrm{V}_{1 / 2 \text {.act }}$ was $0.05 \pm 0.9 \mathrm{mV}$ in vehicle, $-2.58 \pm 1.7 \mathrm{mV}$ by $0.05 \mu \mathrm{M}$ gemcitabine, $-5.2 \pm 1.8 \mathrm{mV}$ by $5 \mu \mathrm{M}$ gemcitabine and $-5.4 \pm 1.4 \mathrm{mV}$ by $50 \mu \mathrm{M}$ gemcitabine. Dose-response curve of $I_{h E R G \text {.tail }}$ suppression by gemcitabine indicates that the median effect of concentration $\left(\mathrm{EC}_{50}\right)$ of gemcitabine to suppress $I_{h E R G}$ was $0.16 \mu \mathrm{M}$ (Figure 2E).

According to the standard clinical methods for gemcitabine application protocol by which patient is being treated, $1,000-1,250 \mathrm{mg} / \mathrm{m}^{2}$ of gemcitabine is to be injected intravenously for 20-30 min once a week [21]. By this application protocol, the maximum serum concentration of gemcitabine reaches approximately $200 \mu \mathrm{M}$ immediately after the injection [22], which follows the concentration declining period for nearly 2 hours. Thus, we mimicked the application protocol of gemcitabine in this in vitro experiment by culturing hERG-HEK cells with $200 \mu \mathrm{M}$ gemcitabine for $2 \mathrm{~h}$ and followed by incubation with gemcitabine-free medium for $22 \mathrm{~h}$ prior to the patch-clamp study. With this experimental protocol, $I_{h E R G}$ was suppressed nearly by $29 \%$ in the representative $I_{h E R G}$ family (Figure $2 C$ ), and by $38 \%$ in the group data (Figure 2D). The result of the normalized $I_{h E R G}$ with this application mimicking clinical protocol is compatibly represented in Figure 2E (filled square).

\subsection{Actions of gemcitabine on $\mathrm{I}_{\mathrm{hERG}}$ activation}

Long-term actions of gemcitabine on $I_{h E R G}$ activation were examined using the envelope of the tail test in hERG-HEK cells treated with vehicle or $0.05 \mu \mathrm{M}$ gemcitabine for $24 \mathrm{~h}$ (Figure 3 and Supplemental table 3). Figure $3 \mathrm{~A}$ indicates representative $I_{h E R G}$ in vehicle and in gemcitabine corresponding to the pulse protocol shown above, where the normalized amplitude of the tail $I_{h E R G}$ was plotted against the pulse duration, yielding the time course of activation process at the test potentials. In Figure 3B inset, the time course of $I_{\text {hERG }}$ activation at the test potential of $+10 \mathrm{mV}$ was fitted to a single exponential function in vehicle and gemcitabine. Activation time constant $\left(\tau_{\mathrm{act}}\right)$ at the potentials of +10 was $0.66 \pm 0.07 \mathrm{~s}$ in vehicle and 0.34 $\pm 0.05 \mathrm{~s}$ in gemcitabine. As demonstrated in $\tau_{\text {act }}-V$ relationship in Figure 3B, activation of the hERG channel was shifted to the direction of hyperpolarization, where the shift was $12.5 \mathrm{mV}$ as assessed at the $\tau_{\text {act }}$ value of $1 \mathrm{~s}$. 


\subsection{Actions of gemcitabine on $\mathrm{I}_{\mathrm{hERG}}$ inactivation}

Long-term actions of gemcitabine on $I_{h E R G}$ inactivation were assessed by applying a conditioning pulse to $+60 \mathrm{mV}$ for $1 \mathrm{~s}$ followed by a brief hyperpolarizing pulse (-120 $\mathrm{mV}$ for $5 \mathrm{~ms}$ ) to allow the hERG channel to recover from inactivation (Figure 4 and Supplemental table 4). Depolarizing test pulses were applied to

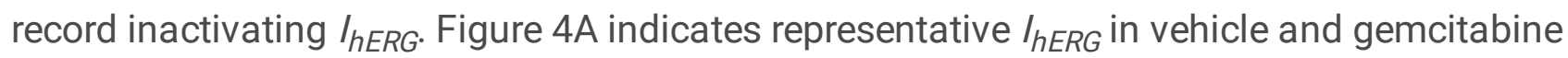
corresponding to the pulse protocol shown above, where the time course of fast inactivating $I_{h E R G}$ was fitted to a single exponential function, yielding a plot demonstrating voltage dependency of the fast time constant of $I_{h E R G}$ inactivation ( $\tau_{\text {inact }}$ ) (Figure 4B). Gemcitabine substantially unaffected $\tau_{\text {inact }}$ at all examined potentials, suggesting that long-term modification of the hERG channel by gemcitabine could not regulate gating properties of the channel from the open state to the inactivation state.

\subsection{Actions of gemcitabine on $\mathrm{I}_{\mathrm{hERG}}$ deactivation}

Deactivation process of the $\mathrm{hERG}$ channel was analyzed by applying long hyperpolarizing test pulses after a conditioning pulse to $+60 \mathrm{mV}$ (Figure $5 \mathrm{~A}$, inset) to assess the long-term actions of gemcitabine. Figure $5 \mathrm{~A}$ demonstrates representative $\mathrm{I}_{\mathrm{hERG}}$ in vehicle and gemcitabine corresponding to the pulse protocol shown above, where the decay phase of instantaneous $I_{h E R G}$ at the beginning of the test pulse could be fitted to a double exponential function. Although the fast phase could be ascribed to the mixture of both inactivation and the deactivation steps based on this pulse protocol, inactivating $I_{h E R G}$ with an extremely fast gating process may has little impact on the decay of $I_{h E R G}[9]$. Because of this reason, the fast component of the time constant was compared as a parameter of channel deactivation $\left(\tau_{\text {deact }}\right)$ between vehicle and gemcitabine treatment. Gemcitabine treatment of hERG-HEK cells did not affect $\tau_{\text {deact }}$ of $I_{h E R G}$ suggesting that gemcitabine has no action on deactivation of the hERG channel as a longterm effect. Namely, long-term modification of the hERG channel by gemcitabine could not regulate gating properties of the channel from the open state to the closed state. Analysis for the fast decay phase amplitude $\left(\mathrm{A}_{\text {fast }}\right)$ also supports the conclusion (Figure $5 \mathrm{~B}$, inset).

\subsection{Actions of gemcitabine on $\mathrm{I}_{\mathrm{h} E \mathrm{RG}}$ reactivation}

Comparison of the process at the recovery from inactivation or reactivation of the $h E R G$ channel in vehicle and by gemcitabine treatment was performed by use of the standard three-stage voltage protocol. A 2-s pulse to $+60 \mathrm{mV}$ was first applied to attain steady-state inactivation, which was followed by a series of test pulses ranging from $-200 \mathrm{mV}$ to $+60 \mathrm{mV}$ for $5 \mathrm{~ms}$ (Figure $6 \mathrm{~A}$ inset). This pulse duration is enough to allow recovery of the channel from inactivation, but too short to allow deactivation. Figure $6 \mathrm{~A}$ demonstrates representative $I_{h E R G}$ in vehicle and gemcitabine treatment corresponding to the pulse protocol shown above, where the peak of the third pulse current was plotted against the potentials of the second pulses, yielding reactivation $1-V$ curves (Figure $6 \mathrm{~B}$ and Supplemental table 6 ). At more negative voltages than $-170 \mathrm{mV}$, a proportion of the channels also deactivate during the second pulse, leading to the observed decrease in the peak currents. Before fitting of the Boltzmann equation, this deactivating 
current was corrected based on the separate protocol such as that shown in Figure 5A to obtain the rates of deactivation at each voltage in the second pulse. With this analysis, voltage dependence of the recovery from steady-state-inactivation or reactivation of $I_{h E R G}$ in vehicle and gemcitabine was nearly identical (Figure 6B), which suggests that modification of the hERG channel by gemcitabine does not affect the reactivation process of the channel. Namely, long-term modification of the hERG channel by gemcitabine could not regulate gating properties of the channel from the inactivated state to the open state.

\subsection{Actions of gemcitabine under the inhibition of glycosylation}

To explore the possible mechanism of gemcitabine on the hERG channel, we examined the long-term actions of gemcitabine under the influence of asparagine $(N$-linked glycosylation inhibition, because altered N-glycosylation levels of circulating glycoproteins were reported in cancer patients with gemcitabine treatment [23]. Also because $\mathrm{N}$-glycosylation reportedly stabilizes hERG channel proteins on the plasma membrane [24], we recorded $I_{\text {hERG }}$ in hERG-HEK cells treated with gemcitabine in the presence or absence of an N-linked glycosylation inhibitor tunicamycin (Figure 7 and Supplemental table 7). Figure 7A demonstrates representative $I_{h E R G}$ in vehicle, in gemcitabine alone $(24 \mathrm{~h})$, in tunicamycin alone (48 h), and in gemcitabine $(24 \mathrm{~h})$ combined with tunicamycin treatment $(48 \mathrm{~h})$ in the culture medium; tunicamycin was applied to the culture medium $24 \mathrm{~h}$ prior to and during the gemcitabine application. Of note, gemcitabine was without effect on $I_{\text {hERG }}$ when $I_{\text {hERG }}$ was highly suppressed by the co-presence of tunicamycin. When terminal $I_{h E R G}$ at the end of each test pulse were plotted against the voltage applied, a bell-shaped relationship was maintained in treatment of gemcitabine, tunicamycin, and gemcitabine combined with tunicamycin, although the potential for the maximum outward current was shifted by the treatment of gemcitabine (Figure 7B), which is consistent with the result in Figure 1E. It is also notable that the differences of the shape of terminal $I_{h E R G}-V$ relationship (Figure 7B) and the tail $I_{h E R G}-V$ relationship (Figure 7C) between tunicamycin and gemcitabine combined with tunicamycin was negligibly small, which suggests that actions of gemcitabine on the hERG channel and actions for the Nglycosylation disruption overlaps significantly. We also noted that gemcitabine treatment significantly shifted the normalized tail $I_{h E R G}$ toward the hyperpolarized direction by $6.4 \mathrm{mV}$, while gemcitabine was unable to shift the tail $I_{\text {hERG }}$ when hERG-HEK cells were simultaneously treated with tunicamycin. These results suggest that action site of gemcitabine and tunicamycin on the hERG channel may not be identical.

\section{Discussion}

In the present study, we found that an anti-cancer drug gemcitabine suppressed $I_{h E R G}$ as a long-term effect $(24 \mathrm{~h})$ in heterologous hERG-HEK cells. The $\mathrm{EC}_{50}$ of gemcitabine designed to suppress $I_{\text {hERG }}$ was $0.16 \mu \mathrm{M}$, which is within the serum concentration of gemcitabine after intravenous bolus injection abased on the standard clinical application protocol [22]. As a long-term effect, gemcitabine modified the voltage 
dependency of the hERG channel activation, while inactivation, deactivation and reactivation gating properties were unaffected by gemcitabine. Gemcitabine treatment-related arrhythmias associated with QT prolongation or risk of torsade de pointes are possibly caused, at least in part, by the N-glycosylation disruption of the hERG channel.

\subsection{Gemcitabine-mediated arrhythmias}

$I_{K r}$ or $I_{h E R G}$ plays a critical role in shaping action potentials in cardiomyocytes, especially the plateau phase and stabilizing action potential durations (APD). Reduction in $I_{h E R G}$ prolongs APD and effective refractory period (ERP), which may result in the destabilization and early termination of reentrant-based arrhythmias $[9,25]$. However, cardiac arrhythmias were often reported in $10 \%$ of patients or more treated with gemcitabine indeed [4]. Gemcitabine is actually known to cause atrial fibrillation [3, 4]. Indeed, the association of gemcitabine with atrial fibrillation is strong and can arise even after the first dose [4]. These observations leave the focus of our attention on the question of how, if gemcitabine prolongs APD, it can also be involved in atrial mechanical function. To put the same question differently: If gemcitabine prolongs atrial contraction time, then how does the mechanism ensure that atrial fibrillation occurs in the case of gemcitabine application? The answer will depend on how atrial contraction regulates atrial/pulmonary vein pressure in human subject. According to human echocardiographic studies, in healthy individuals, left atrial contraction produces forward flow across the mitral valve, as well as a reverse flow in the pulmonary veins $[26,27]$. Left ventricular cavity pressure and compliance during atrial contraction affect forward and reverse atrial flow $[27,28]$. It is accordingly postulated that the reverse flow in the pulmonary veins will become more prominent when left atrial pressure is increased during atrial contraction. Because left atrial cardiomyocytes have large $I_{K r}$ density [29], suppression of $I_{\mathrm{Kr}}$ may participate in the prolongation of contraction time in the atrial tissue, which may cause the increase of atrial pressure and reverse flow in the pulmonary veins. Taken together, a transient suppression of $I_{h E R G}$ by gemcitabine could be a base for the mechanism of atrial fibrillation.

Although the incidence is not high, association of gemcitabine with QT interval prolongations were reported in several studies $[5,6,30]$. The timing of the QT interval at the organism level is related to the APD of ventricular cardiomyocytes acting at the cellular level [31]. Standing on these theoretical viewpoints, we speculate that gemcitabine decreases $I_{h E R G}$ in a long-term application to prolong APD, which could lead to QT prolongation and the risk of torsades de pointes-type arrhythmias. Therefore, caution is highly warranted to avoid conditions that can further lead to QT prolongation such as in hypokalemia, hypothermia, bradycardia, and class III antiarrhythmic drugs etc. in combined with gemcitabine treatment.

\subsection{Gemcitabine as a glycosylation modulator}

Glycosylation of the hERG channels is known to asparagine (N) linked at position N598 [32]. According to literatures, glycosylation of the hERG channel is believed to increase hERG current and stabilize the channel protein on the plasma membrane by decreasing proteolytic susceptibility [33]. In this study, we 
inhibited N-linked glycosylation of the hERG channel in hERG-HEK cells with tunicamycin $(10 \mathrm{mg} / \mathrm{ml}$ for $24 \mathrm{~h}$ ) to confirm the action of glycosylation on the hERG channel in combined with gemcitabine to explore the mechanism of the action. Because gemcitabine could not affect $I_{h E R G}$ when $I_{h E R G}$ was highly suppressed by tunicamycin (Figure 7C), it is plausible to conclude that gemcitabine acts to suppress a pathways of the channel glycosylation to reduce $I_{h E R G}$. We note the fact that disruption in glycan biosynthesis in some tumor cells could profoundly impact multiple molecular events and signaling pathways associated with anticancer drug resistance [34]. Actually, activation of endoplasmic reticulum stress and inhibition of $\mathrm{N}$-glycosylation by tunicamycin enhances susceptibility of some cancer cells to anticancer drugs [35], which implies that some anticancer drugs may act to cancer cells somehow functionally related to protein glycosylation disruption. However, actions of gemcitabine may not be identical to that of tunicamycin on the hERG channel protein based on the fact that gemcitabine shifted the voltage dependency of $I_{h E R G}$ activation toward the hyperpolarized direction whereas tunicamycin was without effect on it (Figure 7D). Since gemcitabine modified the activation gating properties of the $h E R G$ channel (Figure 3), unknown long-term actions of gemcitabine on the hERG channel has been postulated accordingly.

\subsection{Limitation of the study}

There are several limitations in the present study. Although we have demonstrated that gemcitabine has a potential to suppress $I_{h E R G}$ as a long term effect in heterologous expression system, we could not confirm the result on $I_{K r}$ in cardiomyocytes. It is important to keep in mind that transcriptional, post-transcriptional and post-translation modulation pathways for $\mathrm{hERG}$ protein are quite different between heterologous hERG-HEK cells and cardiomyocytes. Also, the structure of glycosylation and its functional implications can vary significantly between different cell types, and between cultured cells and cardiac cells in vivo. Because an incubation technique for the cultivation of adult cardiomyocytes for the duration of $24 \mathrm{~h}$ or longer has not been established, we usually apply electrophysiological studies by use of neonatal cardiomyocyte for these purposes. However, neonatal cardiomyocytes only express very small density of $I_{K n}$ which is not suitable for the evaluation of the long-term effect of gemcitabine on the hERG channel [36]. As such, cardiac cells generated from iPS cells may be suitable for this analysis. In addition, albeit we have obtained $\mathrm{EC}_{50}$ values of gemcitabine to suppress $I_{h E R G}$ a simple comparison of drug concentrations between in vitro study and human serum sample may not be appropriate. Because gemcitabine is a lipophilic drug, assessment of drug efficacy on $I_{h E R G}$ by an in vitro experiment without serum proteins and/or serum lipids may not represent the effect of gemcitabine in in vivo application. Furthermore, a caution would be needed to extrapolate these single cell experiments to human therapeutics. Regarding several glycosylation steps in the endoplasmic reticulum and in the Golgi apparatus, the first step of $\mathrm{N}$-glycosylation in the assemblage of dolichol-linked precursor oligosaccharide at the cytoplasmic side of the endoplasmic reticulum could be blockaded by tunicamycin [37]. As gemcitabine but not tunicamycin modified the activation gating of the hERG channel, it is speculated that gemcitabine regulates other glycosylation step(s) after the $\mathrm{N}$-acetylglucosamine (GlcNAc) phosphotransferase site that tunicamycin can block, although we were unable to identify the target 
molecule(s) of gemcitabine in the whole process of hERG protein glycosylation. Because this study is solely dependent upon electrophysiological evaluation of $I_{h E R G}$ molecular biological analyses for $\mathrm{N}$ glycosylation are obviously needed to address these questions.

\subsection{Conclusions}

Our study revealed that the long-term application of gemcitabine reduces $I_{h E R G}$ possibly through the inhibition of N-linked glycosylation of the channel, which may explain the hitherto unknown pharmacological mechanism of gemcitabine to cause QT prolongation in ECG. Furthermore, excessive reduction of $I_{h E R G}$ by gemcitabine in cardiomyocytes may account for supraventricular arrhythmogenicity of this drug as documented in clinical reports.

\section{Declarations}

Author Contributions: M.W., P.W. and X.Z. contributed equally to this manuscript. Conceptualization, K.O.; methodology, M.W., P.W., X.Z. and Y.L.; validation, Y.L., M.Z. and G.L.; formal analysis, M.W.; investigation, M.W., P.W., H.O. and X.Z.; data curation, K.Y., S.K., and T.K.; writing-original draft preparation, K.O. The authors declare that all data were generated in-house and that no paper mill was used. All authors have read and agreed to the published version of the manuscript.

Competing Interests: None.

Funding: This research received no external funding.

Institutional Review Board Statement: The experimental protocol was approved as "a non-animal study" in advance by the Ethics Review Committee for Animal Experimentation of Oita University School of Medicine.

Data Availability Statement: The data in this study are available from the corresponding author on reasonable request.

Acknowledgments: The HEK293 cells expressing hERG are a kind gift from Prof. Imaizumi Yuji, Nagoya City University, Graduate School of Pharmaceutical Sciences.

Conflicts of Interest: The authors declare that they have no conflict of interest.

\section{References}

1. Plunkett W, Huang P, Xu YZ, Heinemann V, Grunewald R, Gandhi V. Gemcitabine: metabolism, mechanisms of action, and self-potentiation. Semin. Oncol. 1995, 22 (4 Suppl 11), 3-10.

2. Hilmi M, Ederhy S, Waintraub X, Funck-Brentano C, Cohen A, Vozy A, Lebrun-Vignes B, Moslehi J, Nguyen LS, Salem JE. Cardiotoxicity Associated with Gemcitabine: Literature Review and a Pharmacovigilance Study. Pharmaceuticals (Basel). 2020, 13, 325. 
3. Santini D, Tonini G, Abbate A, Di Cosimo S, Gravante G, Vincenzi B, Campisi C, Patti G, Di Sciascio G. Gemcitabine-induced atrial fibrillation: a hitherto unreported manifestation of drug toxicity. Ann. Oncol. 2000, 11, 479-481.

4. Gridelli C, Cigolari S, Gallo C, Manzione L, lanniello GP, Frontini L, Ferraù F, Robbiati SF, Adamo V, Gasparini G, Novello S, Perrone F; MILES Investigators. Activity and toxicity of gemcitabine and gemcitabine + vinorelbine in advanced non-small-cell lung cancer elderly patients: Phase II data from the Multicenter Italian Lung Cancer in the Elderly Study (MILES) randomized trial. Lung Cancer. 2001, $31,277-284$.

5. Gridelli C, Novello S, Zilembo N, Luciani A, Favaretto AG, De Marinis F, Genestreti G, Crinò L, Grossi F, Caffo O, Ferraù F, Cruciani G, Brandes AA, Galetta D, Barni S, Fasola G, Cerea G, Ferrari S, lannacone C, Ciardiello F. Phase II randomized study of vandetanib plus gemcitabine or gemcitabine plus placebo as first-line treatment of advanced non-small-cell lung cancer in elderly patients. J. Thorac. Oncol. 2014, 9, 733-737.

6. Rademaker-Lakhai JM, Beerepoot LV, Mehra N, Radema SA, van Maanen R, Vermaat JS, Witteveen EO, Visseren-Grul CM, Musib L, Enas N, van Hal G, Beijnen JH, Schellens JH, Voest EE. Phase I pharmacokinetic and pharmacodynamic study of the oral protein kinase $\mathrm{C}$ beta-inhibitor enzastaurin in combination with gemcitabine and cisplatin in patients with advanced cancer. Clin. Cancer Res. 2007, 13, 4474-4481.

7. Santoro A, Gebbia V, Pressiani T, Testa A, Personeni N, Arrivas Bajardi E, Foa P, Buonadonna A, Bencardino K, Barone C, Ferrari D, Zaniboni A, Tronconi MC, Cartenì G, Milella M, Comandone A, Ferrari S, Rimassa L. A randomized, multicenter, phase II study of vandetanib monotherapy versus vandetanib in combination with gemcitabine versus gemcitabine plus placebo in subjects with advanced biliary tract cancer: the VanGogh study. Ann. Oncol. 2015, 26, 542-547.

8. Kindler HL, loka T, Richel DJ, Bennouna J, Létourneau R, Okusaka T, Funakoshi A, Furuse J, Park YS, Ohkawa S, Springett GM, Wasan HS, Trask PC, Bycott P, Ricart AD, Kim S, Van Cutsem E. Axitinib plus gemcitabine versus placebo plus gemcitabine in patients with advanced pancreatic adenocarcinoma: a double-blind randomised phase 3 study. Lancet Oncol. 2011, 12, 256-262.

9. Vandenberg JI, Perry MD, Perrin MJ, Mann SA, Ke Y, Hill AP. hERG K ${ }^{+}$channels: structure, function, and clinical significance. Physiol. Rev. 2012, 92, 1393-1478.

10. Kirchhof P, Eckardt L, Franz MR, Mönnig G, Loh P, Wedekind H, Schulze-Bahr E, Breithardt G, Haverkamp W. Prolonged atrial action potential durations and polymorphic atrial tachyarrhythmias in patients with long QT syndrome. J. Cardiovasc. Electrophysiol. 2003, 14, 1027-1033.

11. Johnson JN, Tester DJ, Perry J, Salisbury BA, Reed CR, Ackerman MJ. Prevalence of early-onset atrial fibrillation in congenital long QT syndrome. Heart Rhythm. 2008, 5, 704-709.

12. Zellerhoff S, Pistulli R, Mönnig G, Hinterseer M, Beckmann BM, Köbe J, Steinbeck G, Kääb S, Haverkamp W, Fabritz L, Gradaus R, Breithardt G, Schulze-Bahr E, Böcker D, Kirchhof P. Atrial arrhythmias in long-QT syndrome under daily life conditions: a nested case control study. J. Cardiovasc. Electrophysiol. 2009, 20, 401-407. 
13. Mandyam MC, Soliman EZ, Alonso A, Dewland TA, Heckbert SR, Vittinghoff E, Cummings SR, Ellinor PT, Chaitman BR, Stocke K, Applegate WB, Arking DE, Butler J, Loehr LR, Magnani JW, Murphy RA, Satterfield S, Newman AB, Marcus GM. The QT interval and risk of incident atrial fibrillation. Heart Rhythm. 2013, 10, 1562-1568.

14. Platonov PG, McNitt S, Polonsky B, Rosero SZ, Zareba W. Atrial fibrillation in long QT syndrome by genotype. Circ. Arrhythm. Electrophysiol. 2019, 12, e007213.

15. Ma F, Takanari H, Masuda K, Morishima M, Ono K. Short- and long-term inhibition of cardiac inwardrectifier potassium channel current by an antiarrhythmic drug bepridil. Heart Vessels. 2016, 31, 11761184.

16. Masuda K, Takanari H, Morishima M, Ma F, Wang Y, Takahashi N, Ono K. Testosterone-mediated upregulation of delayed rectifier potassium channel in cardiomyocytes causes abbreviation of QT intervals in rats. J. Physiol. Sci. 2018, 68, 759-767.

17. Morishima M, Iwata E, Nakada C, Tsukamoto Y, Takanari H, Miyamoto S, Moriyama M, Ono K. Atrial fibrillation-mediated upregulation of miR-30d regulates myocardial electrical remodeling of the Gprotein-gated K ${ }^{+}$channel, IK.ACh. Circ. J. 2016, 80, 1346-1355.

18. Liu S, Rasmusson RL, Campbell DL, Wang S, Strauss HC. Activation and inactivation kinetics of an E4031-sensitive current from single ferret atrial myocytes. Biophys. J. 1996, 70, 2704-1715.

19. Shibasaki T. Conductance and kinetics of delayed rectifier potassium channels in nodal cells of the rabbit heart. J Physiol. 1987, 387, 227-250.

20. Gintant GA. Two components of delayed rectifier current in canine atrium and ventricle. Does $I_{K s}$ play a role in the reverse rate dependence of class III agents? Circ. Res. 1996, 78, 26-37.

21. Sandler A, Ettinger DS. Gemcitabine: single-agent and combination therapy in non-small cell lung cancer. Oncologist. 1999, 4, 241-251.

22. Veerman G, Ruiz van Haperen VW, Vermorken JB, Noordhuis P, Braakhuis BJ, Pinedo HM, Peters GJ. Antitumor activity of prolonged as compared with bolus administration of 2',2'-difluorodeoxycytidine in vivo against murine colon tumors. Cancer Chemother. Pharmacol. 1996, 38, 335-342.

23. Miyahara K, Nouso K, Morimoto Y, Kinugasa H, Kato H, Yamamoto N, Tsutsumi K, Kuwaki K, Onishi H, Ikeda F, Nakamura S, Shiraha H, Takaki A, Nakahara T, Miura Y, Asada H, Amano M, Nishimura S, Yamamoto K. Prognostic value of altered N-glycosylation of circulating glycoproteins in patients with unresectable pancreatic cancer treated with gemcitabine. Pancreas. 2015, 44, 551-556.

24. Lamothe SM, Hulbert M, Guo J, Li W, Yang T, Zhang S. Glycosylation stabilizes hERG channels on the plasma membrane by decreasing proteolytic susceptibility. FASEB J. 2018, 32, 1933-1943.

25. Jeevaratnam K, Chadda KR, Huang CL, Camm AJ. Cardiac potassium channels: Physiological insights for targeted therapy. J. Cardiovasc. Pharmacol. Ther. 2018, 23, 119-129.

26. Klein AL, Tajik AJ. Doppler assessment of pulmonary venous flow in healthy subjects and in patients with heart disease. J. Am. Soc. Echocardiogr. 1991, 4, 379-392. 
27. Bukachi F, Waldenström A, Mörner S, Lindqvist P, Henein MY, Kazzam E. Pulmonary venous flow reversal and its relationship to atrial mechanical function in normal subjects-Umeå General Population Heart Study. Eur. J. Echocardiogr. 2005, 6, 107-116.

28. Nishimura RA, Abel MD, Hatle LK, Tajik AJ. Relation of pulmonary vein to mitral flow velocities by transesophageal Doppler echocardiography. Effect of different loading conditions. Circulation. 1990, 81, 1488-1497.

29. Li D, Zhang L, Kneller J, Nattel S. Potential ionic mechanism for repolarization differences between canine right and left atrium. Circ. Res. 2001, 88, 1168-1175.

30. Vandetanib gemcitabine or placebo plus gemcitabine or vandetanib monotherapy in advanced biliary tract cancer (VANGOGH) Vandetanib gemcitabine or placebo plus gemcitabine or vandetanib monotherapy in advanced biliary tract cancer - tabular view - ClinicalTrials.gov

31. Witchel HJ, Hancox JC. Familial and acquired long QT syndrome and the cardiac rapid delayed rectifier potassium current. Clin. Exp. Pharmacol. Physiol. 2000, 27, 753-766.

32. Gong Q, Anderson CL, January CT, Zhou Z. Role of glycosylation in cell surface expression and stability of HERG potassium channels. Am J. Physiol. Heart. Circ. Physiol. 2002, 283, H77-H84.

33. Petrecca K, Atanasiu R, Akhavan A, Shrier A. N-linked glycosylation sites determine HERG channel surface membrane expression. J. Physiol. 1999, 515, 41-48.

34. Chen R, Lai LA, Sullivan Y, Wong M, Wang L, Riddell J, Jung L, Pillarisetty VG, Brentnall TA, Pan S. Disrupting glutamine metabolic pathways to sensitize gemcitabine-resistant pancreatic cancer. Sci. Rep. 2017, 7, 7950.

35. Ling YH, Li T, Perez-Soler R, Haigentz M Jr. Activation of ER stress and inhibition of EGFR Nglycosylation by tunicamycin enhances susceptibility of human non-small cell lung cancer cells to erlotinib. Cancer Chemother. Pharmacol. 2009, 64, 539-548.

36. Wang Y, Morishima M, Li D, Takahashi N, Saikawa T, Nattel S, Ono K. Binge alcohol exposure triggers atrial fibrillation through T-type $\mathrm{Ca}^{2+}$ channel upregulation via protein kinase $\mathrm{C}$ (PKC) / glycogen synthesis kinase 3b (GSK3b) / nuclear factor of activated T-cells (NFAT) Signaling - An experimental account of holiday heart syndrome. Circ. J. 2020, 84, 1931-1940.

37. Skrenkova K, Lee S, Lichnerova K, Kaniakova M, Hansikova H, Zapotocky M, Suh YH, Horak M. Nglycosylation regulates the trafficking and surface mobility of GluN3A-containing NMDA receptors. Front. Mol. Neurosci. 2018, 11, 188.

\section{Figures}




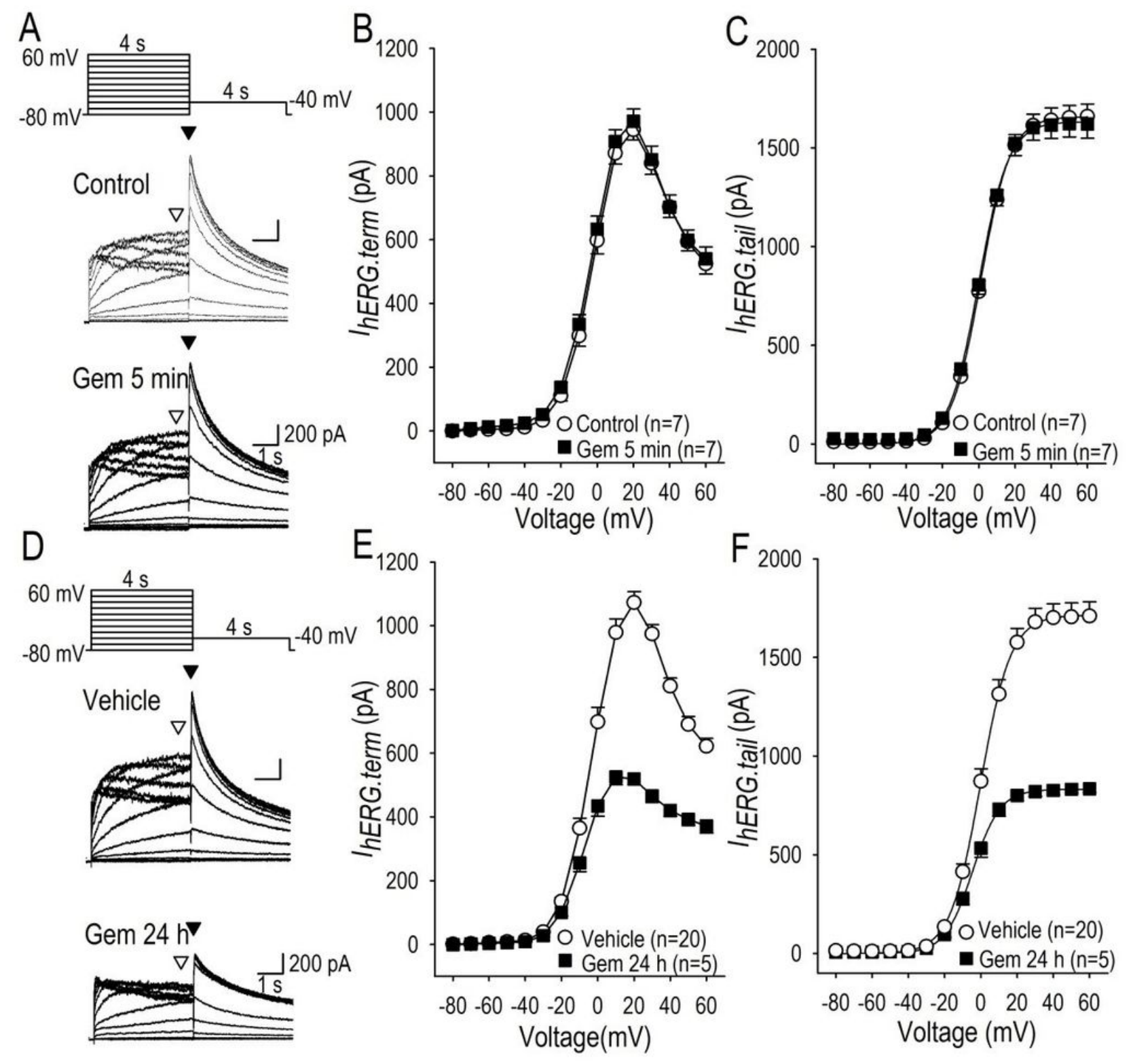

Figure 1

Acute- and long-term effect of gemcitabine on IhERG or rapidly activating delayed rectifier potassium current (IKr). (A) Representative IhERG family traces in the control and during the acute (5 min) application of gemcitabine (Gem) $(50 \mu \mathrm{M})$ are shown. Pulse protocol is shown above. (B) The relationship between terminal IhERG (IhERG.term) measured at the end of each test pulse indicated by hollow arrowheads in panel $A(\nabla)$ and the test pulse potential $(V)$ constructed by using group data are shown as IhERG.term-V relationship in control ( $\square$ ) and during the acute application of $50 \mu \mathrm{M}$ gemcitabine in $5 \mathrm{~min}(\boldsymbol{\square})$. The maximum current amplitude of IhERG.term at $+20 \mathrm{mV}$ was $945 \pm 31 \mathrm{pA}$ in control ( $\square$ ), and was $972 \pm 38$ pA with $50 \mu \mathrm{M}$ gemcitabine ( $\mathbf{\square})$ in $5 \mathrm{~min}$. (C) The relationship between tail lhERG 
(IhERG.tail) measured at the beginning of the third pulse at $-40 \mathrm{mV}$ indicated by filled arrowheads in panel $A(\boldsymbol{\nabla})$ and test pulse potential $(\mathrm{V})$ constructed by using group data are shown as IhERG.tail-V relationship in control ( $\square$ ) and during the acute application of $50 \mu \mathrm{M}$ gemcitabine in $5 \mathrm{~min}(\boldsymbol{\square})$. (D) Representative IhERG family traces of the control and long-term $(24 \mathrm{~h})$ application of gemcitabine $(50 \mu \mathrm{M})$ are shown. Pulse protocol is shown above. (E) The IhERG.term-V relationship constructed by using group data in control and long-term application of $50 \mu \mathrm{M}$ gemcitabine for $24 \mathrm{~h}$. The maximum current amplitude of IhERG.terml was significantly reduced by $50 \%$ from $1072 \pm 34$ pA (vehicle) to $540 \pm 25$ pA (gemcitabine), where the potential for the maximum current was shifted to the hyperpolarized potentials from $+20 \mathrm{mV}$ (vehicle) to $+10 \mathrm{mV}$ (gemcitabine). (F) The IhERG.tail-V relationship constructed by using group data in control and long-term application of $50 \mu \mathrm{M}$ gemcitabine for $24 \mathrm{~h}$. The maximum current amplitude of IhERG.tail at $60 \mathrm{mV}$ was significantly reduced by $51 \%$ from $1709 \pm 73 \mathrm{pA}$ (vehicle) to $846 \pm 17 \mathrm{pA}$ (gemcitabine). Numbers of cell are shown in parentheses. Values represent the mean \pm SE.

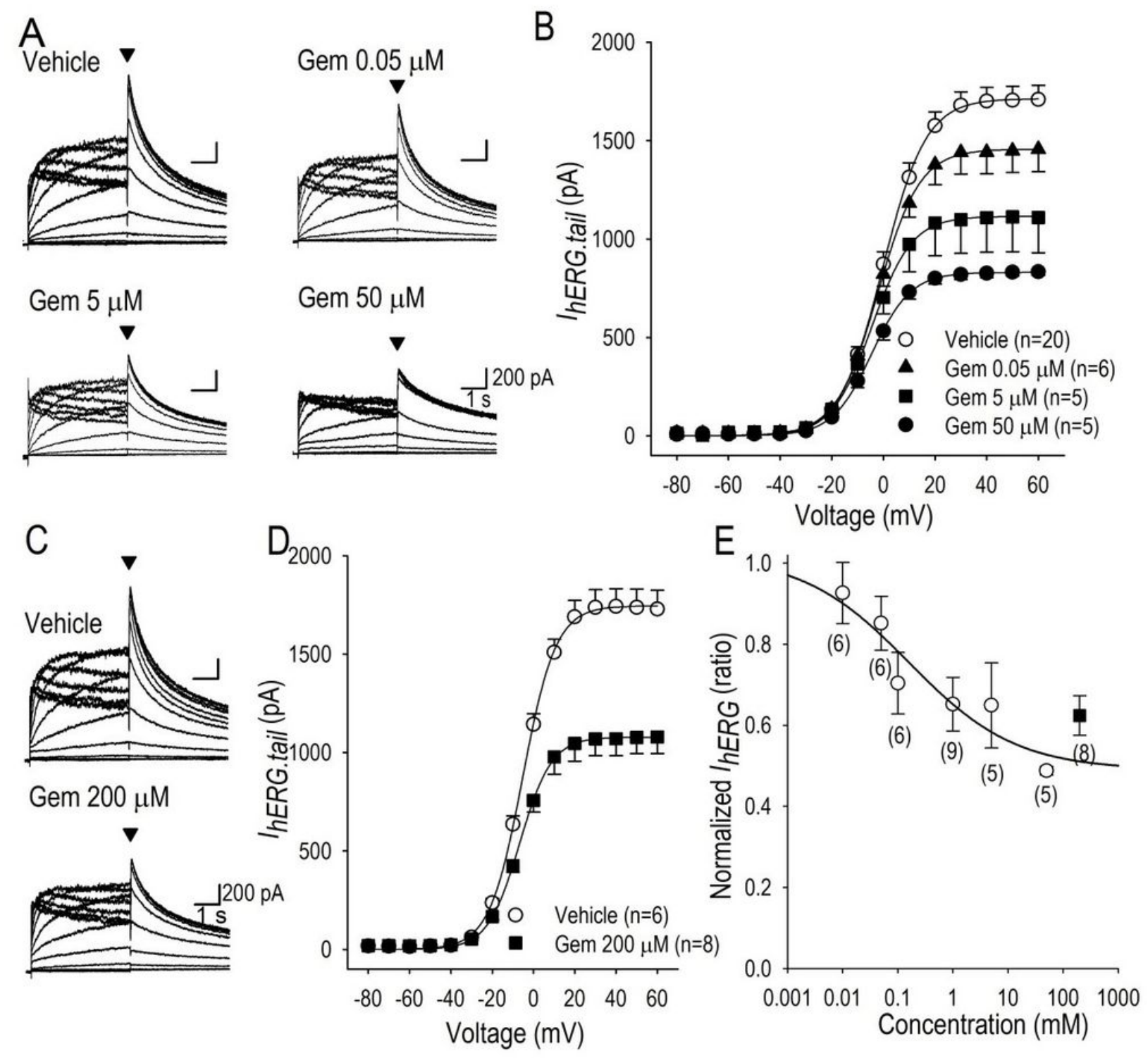




\section{Figure 2}

Dose-dependent inhibition of IhERG by long-term application of gemcitabine. (A) Representative lhERG family traces in vehicle, $0.05 \mu \mathrm{M}, 5 \mu \mathrm{M}$ and $50 \mu \mathrm{M}$ gemcitabine (Gem) applied for $24 \mathrm{~h}$. Pulse protocol was identical to that shown in Figure 1A. (B) The IhERG.tail-V relationship constructed by using group

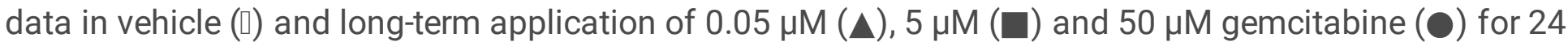
h. IhERG.tail was assessed by the amplitude of the tail current of IhERG indicated by the filled arrowheads in panel (A). (C) Representative IhERG family traces in vehicle and $200 \mu \mathrm{M}$ gemcitabine applied for $2 \mathrm{~h}$. In this application protocol, hERG-HEK cells were incubated with $200 \mu \mathrm{M}$ gemcitabine for $2 \mathrm{~h}$, followed by incubation with gemcitabine-free culture medium for $22 \mathrm{~h}$. (D) The IhERG.tail-V relationship constructed by group data in vehicle $(\square)$ and $200 \mu \mathrm{M}$ gemcitabine $(\square)$ applied by the application method described in panel (C). The maximum IhERG.tail was reduced by $38 \%$ from $1728 \pm 96 \mathrm{pA}$ (vehicle) to $1079 \pm 84 \mathrm{pA}$ (gemcitabine). (E) Fractional changes in IhERG measured at $+60 \mathrm{mV}$ in IhERG.tail were plotted against the concentration of gemcitabine applied for $24 \mathrm{~h}(\mathrm{\square})$ and $2 \mathrm{~h}(\boldsymbol{\square})$ based on the method mimicking clinical application protocol as described in panel (C). Numbers of cell are shown in parentheses. Values represent the mean \pm SE.
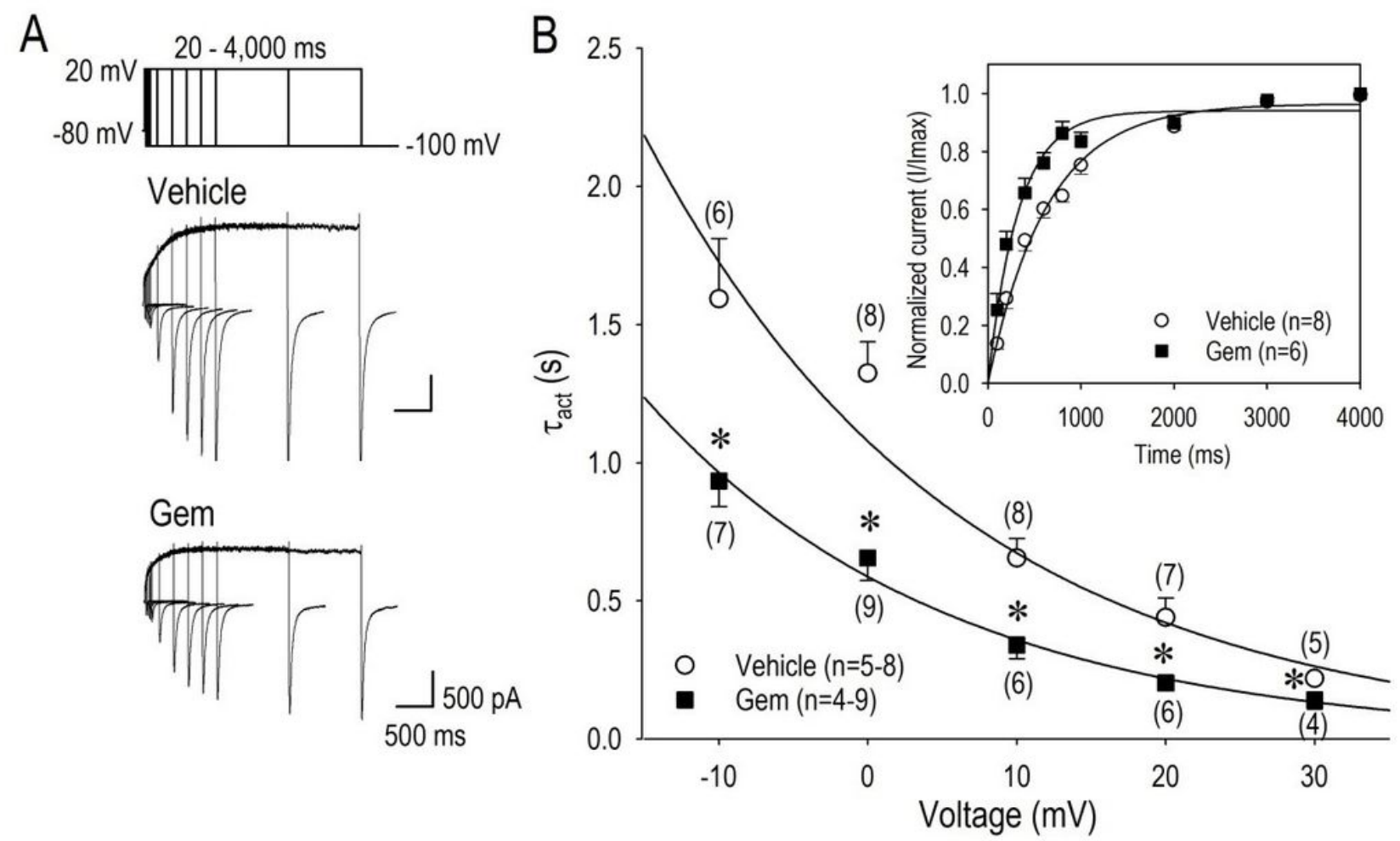

\section{Figure 3}

Actions of gemcitabine on IhERG activation gating. (A) Representative IhERG traces elicited by pulse protocol shown above, which displays time course of IhERG activation measures by envelope of tail test 
in vehicle and in $0.05 \mu \mathrm{M}$ gemcitabine (Gem) for $24 \mathrm{~h}$. (B) Activation time constant (tact)- $V$ relationship in vehicle ( $\square$ ) and gemcitabine ( $\boldsymbol{\square})$, where tact at each test potential was obtained by a single exponential fitting curve in a plot of pulse duration $(20-4,000 \mathrm{~ms})$ versus IhERG.tail. An inset shows a fitting curve of the activating IhERG at the potentials of $+10 \mathrm{mV}$, yielding tact of $0.66 \mathrm{~s}$ for vehicle and of $0.34 \mathrm{~s}$ for gemcitabine. Data of tact were further fitted by a single exponential curve, which yields IhERG activation rate constant of $21.3 \mathrm{mV}$ for vehicle $(\square)$ and $20.2 \mathrm{mV}$ for gemcitabine ( $\boldsymbol{\square}$ ). Numbers of cell are shown in parentheses. Values represent the mean \pm SE. ${ }^{*} p<0.05$ vs. Vehicle.
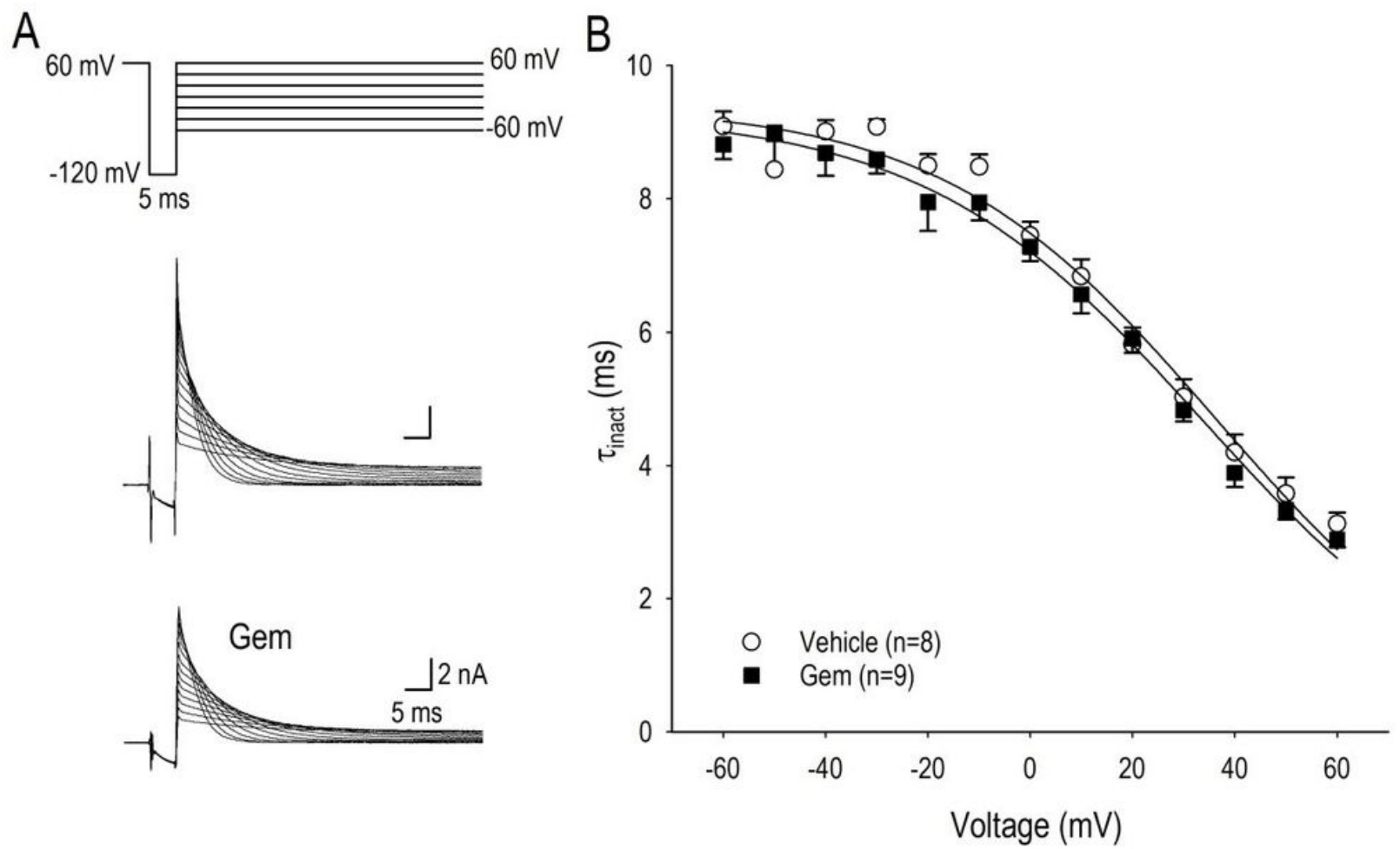

\section{Figure 4}

Actions of gemcitabine on IhERG inactivation gating. (A) Representative IhERG traces elicited by pulse protocol shown above, which displays voltage-dependent decay or inactivation of IhERG.tail in vehicle and $0.05 \mu \mathrm{M}$ gemcitabine (Gem) for $24 \mathrm{~h}$. (B) Relationship between time constant of the decay phase of IhERG.tail or tinact and the test pulse potential in vehicle ( $\square$ ) and gemcitabine ( $\square$ ). Numbers of cell are shown in parentheses. Values represent the mean $\pm \mathrm{SE}$. 

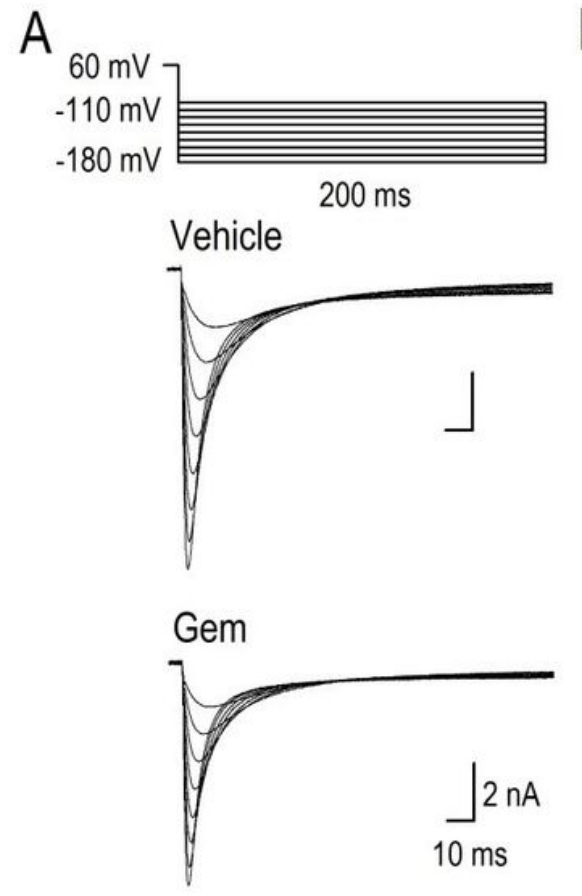

B

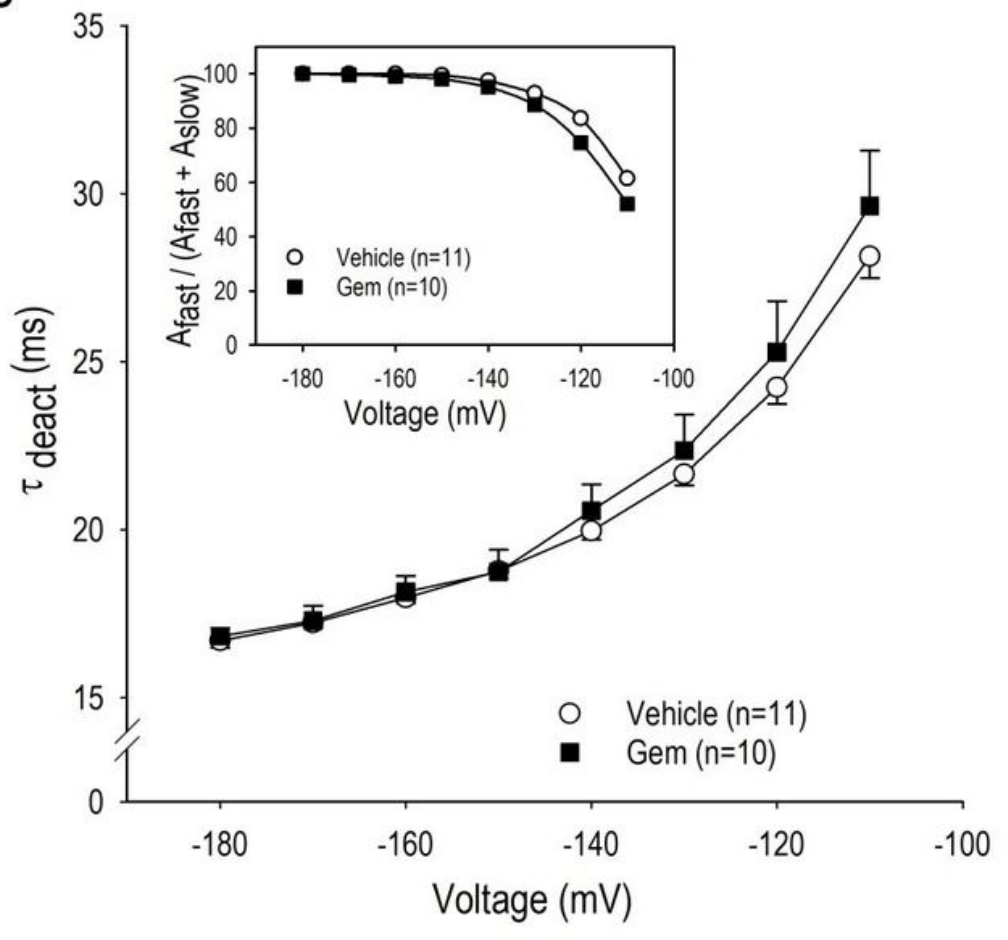

Figure 5

Actions of gemcitabine on IhERG deactivation gating. (A) Representative IhERG traces elicited by pulse protocol shown above, which displays deactivating phase of IhERG in vehicle and $0.05 \mu \mathrm{M}$ gemcitabine (Gem) for $24 \mathrm{~h}$. (B) Relationship between time constant of the decay phase of IhERG or tdeact and the test pulse potential in vehicle $(\square)$ and gemcitabine $(\square)$. An inset shows a ration of the fast component of the decay amplitude (Afast) to whole decay amplitude (Afast + Aslow). Although the decaying phase was fitted by a sum of two exponential components, $\tau$ for the fast component or the main component of the decay phase was assessed as tdeact for the deactivating gating properties. Numbers of cell are shown in parentheses. Values represent the mean $\pm \mathrm{SE}$. 


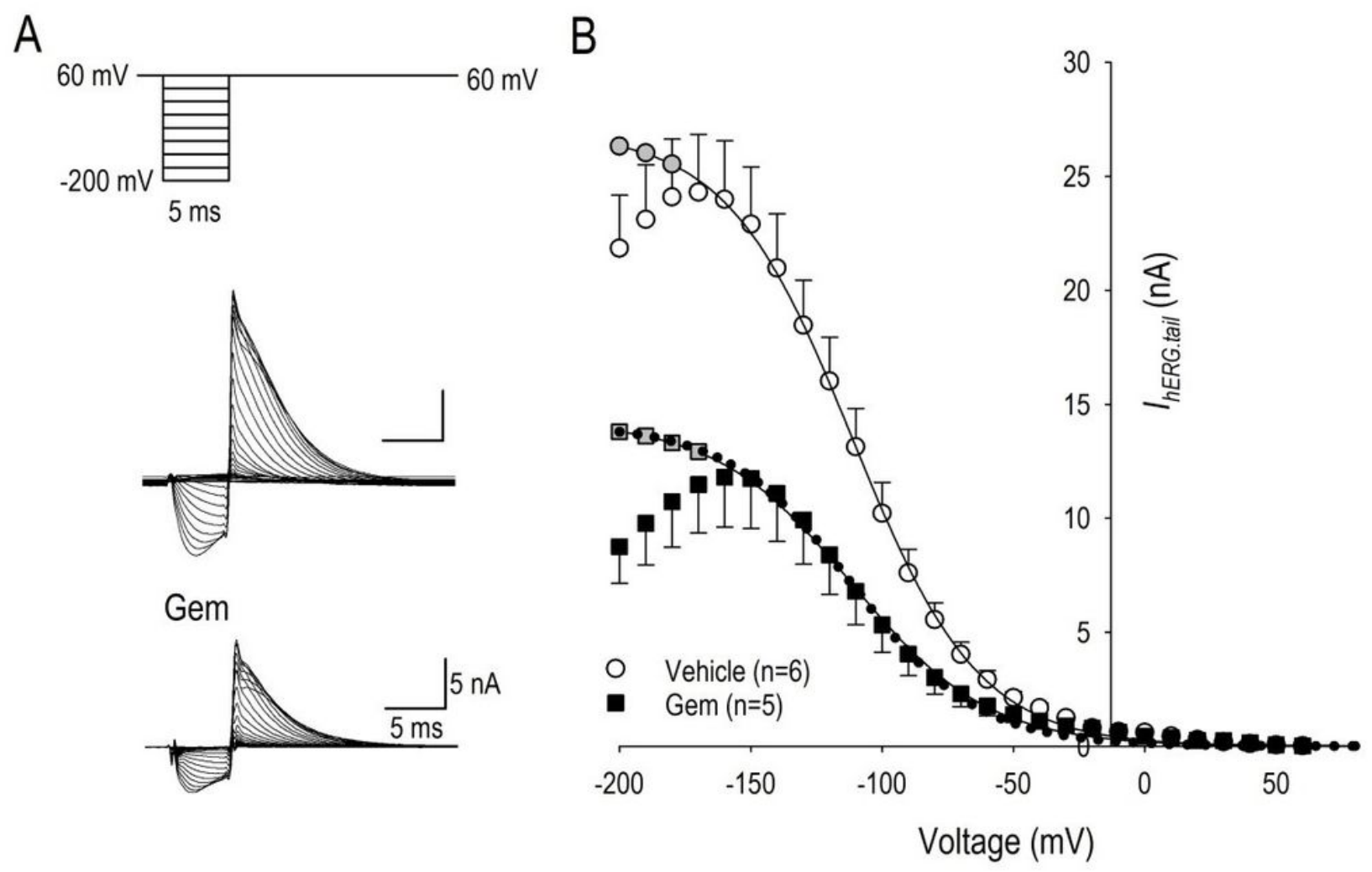

Figure 6

Actions of gemcitabine on IhERG reactivation gating. (A) Representative IhERG traces elicited by pulse protocol shown above, which displays reactivating IhERG in response to the conditioning potentials (-200 $\mathrm{mV}-+60 \mathrm{mV}$ ) in vehicle and $0.05 \mu \mathrm{M}$ gemcitabine (Gem) for $24 \mathrm{~h}$. (B) Relationship between amplitude of reactivating IhERG.tail and the conditioning pulse potentials in vehicle ( $\square$ ) and gemcitabine ( $\square$ ). Gray filled circles and gray filled squares represent corrected data set after the replacement of IhERG deactivating component. Each solid curve was a product of a fit by Boltzmann equation, and dotted line was drawn by Boltzmann fitting curve for vehicle data multiplied by 0.45 that representing the ratio (gemcitabine-lhERG / vehicle-lhERG) at -200 mV. Numbers of cell are shown in parentheses. Values represent the mean \pm SE. 


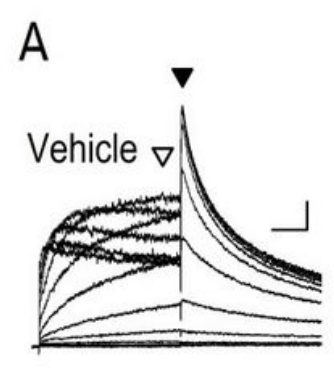

Tunicamycin
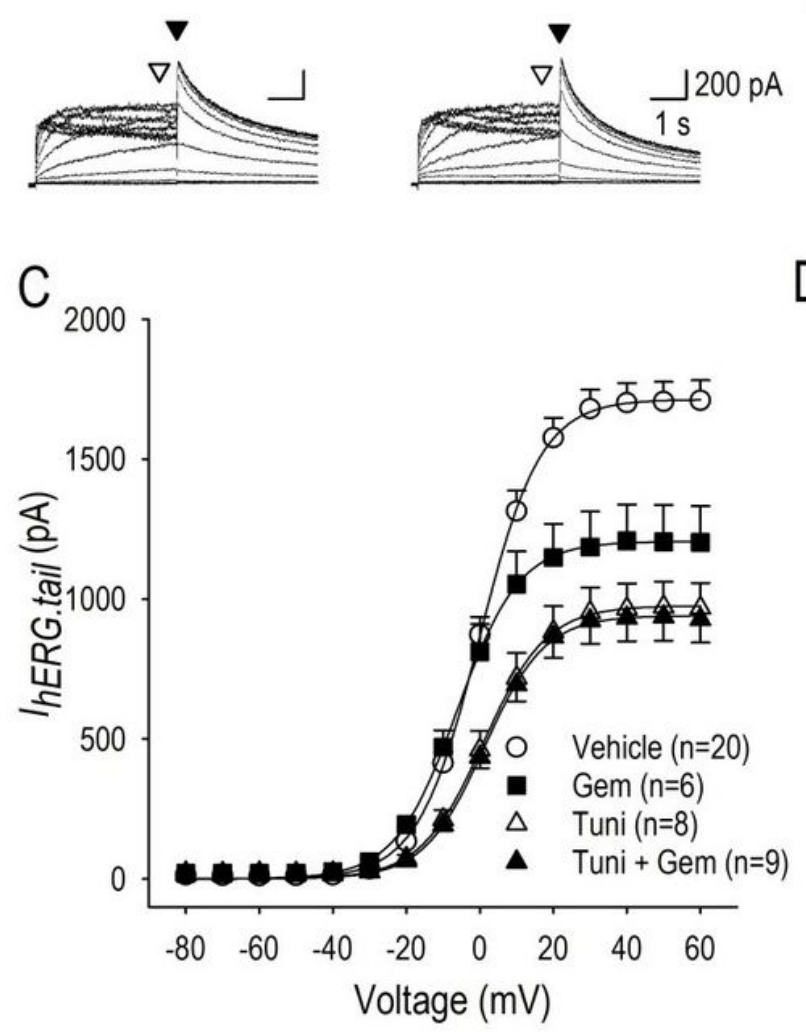
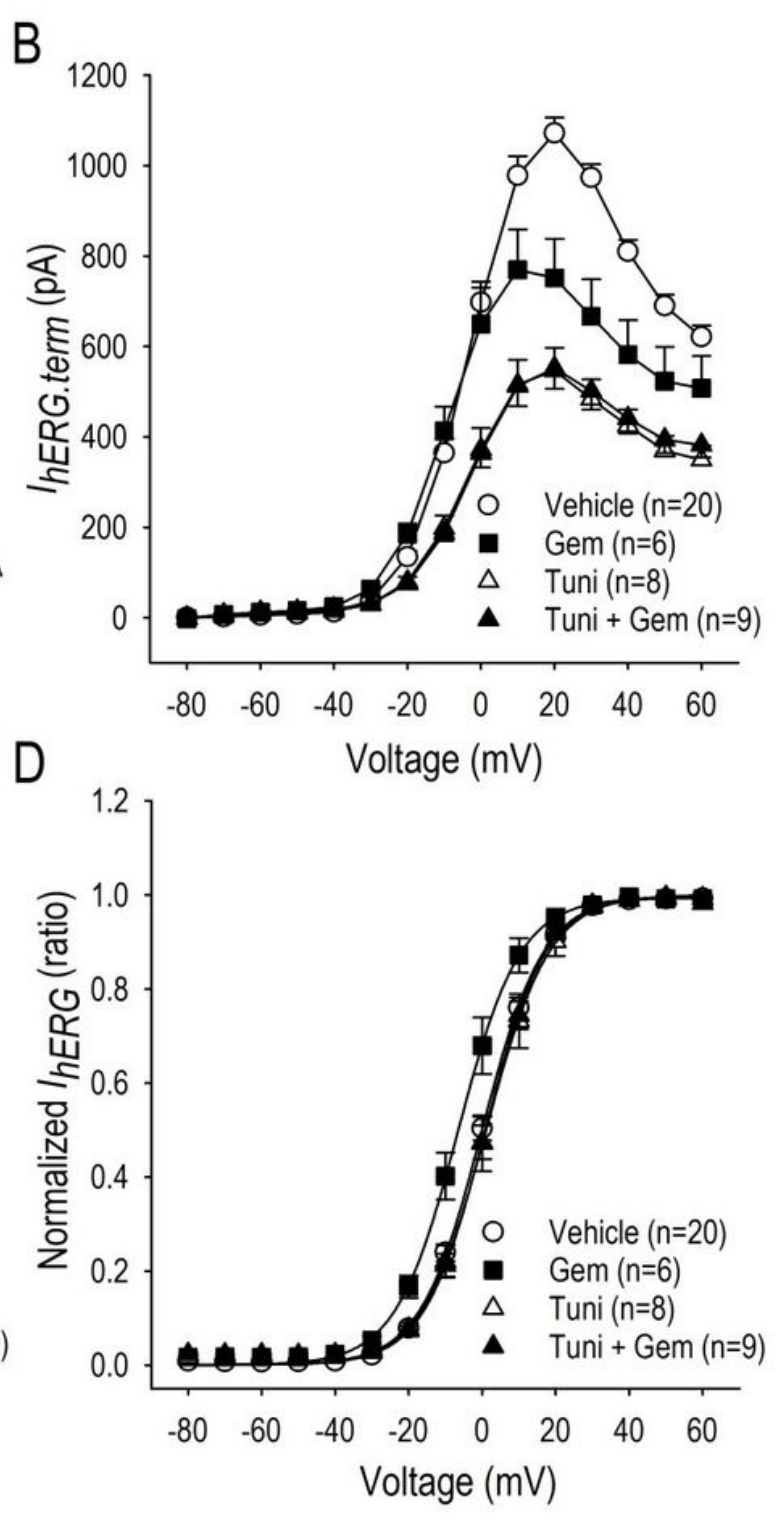

\section{Figure 7}

Actions of gemcitabine on IhERG in combined with tunicamycin. (A) Representative lhERG traces in vehicle, $0.1 \mu \mathrm{M}$ gemcitabine (Gem) $(24 \mathrm{~h}), 0.5 \mu \mathrm{g} / \mathrm{ml}$ tunicamycin (Tuni) (48 h), and $0.1 \mu \mathrm{M}$ gemcitabine $(24 \mathrm{~h})$ with $0.5 \mu \mathrm{g} / \mathrm{ml}$ tuni-camycin $(48 \mathrm{~h})$. Tunicamycin was applied to the culture medium $24 \mathrm{~h}$ prior to and during the application of gemcita-bine for $24 \mathrm{~h}$. (B) The relationship between IhERG.term measured at the end of the test pulse (indicated by hollow arrow-heads in panel $A, \nabla$ ) and test pulse potential $(\mathrm{V})$ constructed by using group data in vehicle ( ()$, 0.1 \mu \mathrm{M}$ gemcitabine $(\boldsymbol{\square}), 0.5 \mu \mathrm{g} / \mathrm{ml}$ tunicamycin $(\boldsymbol{\Delta})$, and gemcitabine with tunicamycin $(\nabla)$. (C) The relationship between IhERG.tail meas-ured at the beginning of the third pulse at $-40 \mathrm{mV}$ (indicated by filled arrowheads in panel $\mathrm{A}, \boldsymbol{\nabla}$ ) and test pulse po-tential $(\mathrm{V})$ constructed by using group data are shown as IhERG.tail-V relationship in vehicle ( $($ ) , $0.1 \mu \mathrm{M}$ gemcitabine 
$(\boldsymbol{\square}), 0.5 \mu \mathrm{g} / \mathrm{ml}$ tunicamycin ( $\boldsymbol{\Delta})$, and gemcitabine with tunicamycin (区). (D) Normalized lhERG.tail-V relationship based on data in panel $C$ for vehicle $(\square), 0.1 \mu \mathrm{M}$ gemcitabine $(\boldsymbol{\square}), 0.5 \mu \mathrm{g} / \mathrm{ml}$ tunicamycin $(\boldsymbol{\Delta})$, and gemcitabine with tunicamy-cin ( () . V1/2 was $0.1 \pm 0.1 \mathrm{mV}$ for vehicle, $6.3 \pm 2.0 \mathrm{mV}$ for gemcitabine, $1.2 \pm 2.2 \mathrm{mV}$ for tunicamycin and $0.8 \pm 1.2 \mathrm{mV}$ for tunicamycin with gemcitabine. Numbers of cell are shown in parentheses. Values represent the mean \pm SE.

\section{Supplementary Files}

This is a list of supplementary files associated with this preprint. Click to download.

- SupplementalTable1.xlsx

- SupplementalTable2.xlsx

- SupplementalTable3.xlsx

- SupplementalTable4.xlsx

- SupplementalTable5.xIsx

- SupplementalTable6.xlsx

- SupplementalTable7.xlsx 